\title{
Combination of salbutamol inhalational powder and tablets in asthma
}

\author{
K GRIMWOOD, D M FERGUSSON, AND K P DAWSON \\ Department of Paediatrics, Christchurch Clinical School, of Medicine, Christchurch Hospital, Christchurch, \\ New Zealand
}

SUMMARY A double-blind cross-over trial was conducted to assess the effects of salbutamol administered by inhalation of dry powder, by tablet, and combined tablet and inhalational powder in a sample of 18 severely asthmatic children. The combined treatment had a rapid onset of effect and sustained action. The onset of action of the tablet treatment was less rapid but sustained, whereas the inhalational powder treatment had rapid onset but fairly short action. The response characteristics of the combined treatment were shown to be an additive function of its tablet and inhaled components. Children on the combined or tablet treatment showed a significant, but slight, increase in pulse rate. Few other side effects were observed.

The ideal drug in the management of asthma has a rapid onset and sustained action. Studies of the response characteristics of inhaled and tablet administered preparations show that both methods fall short of this ideal. Inhaled preparations have a rapid onset of action but tend to lose efficacy rapidly, whereas tablets have a slower onset of action but their effect is more sustained. ${ }^{1-3}$ Few studies have examined the effects of combination therapy and their results have been conflicting, either indicating an additional benefit without side effects, ${ }^{4}$ or no significant benefit over inhalational therapy alone and an increased incidence of adverse side effects. ${ }^{56}$

We report on a controlled trial of salbutamol administered by inhalational powder, in a tablet form, and by combined inhalational powder and tablet. The aim was to determine whether the combined tablet and inhalational powder administration produced a treatment having the desired characteristics of rapid onset of effect and sustained action.

\section{Subjects and methods}

We studied 18 (10 girls and 8 boys) children aged 5 to 12 (mean $8 \cdot 3$ ) years who were regular patients at a hospital asthma clinic for severe, recurrent, or chronic asthma (grade C or D). ${ }^{7}$ Mean duration of symptoms was 5.9 (range 3-9) years. All were receiving continuous bronchodilator treatment and other prophylaxis.

A double-blind cross-over design was used in which the children received salbutamol administered in three ways on three separate sessions spaced 3 to 4 days apart. The treatment order was randomised and the treatments were: (1) Oral salbutamol administered as a $4 \mathrm{mg}$ tablet plus a dummy glucose powder administered by a rotahaler. (2) Inhaled salbutamol powder $(400 \mu \mathrm{g}$ capsule) administered by a rotahaler plus a dummy glucose tablet. (3) Oral salbutamol administered as a $4 \mathrm{mg}$ tablet plus inhaled salbutamol $(400 \mu \mathrm{g})$ delivered by a rotahaler.

No child received sympathometics within 6 hours, or theophylline within 15 hours of each trial. Sodium cromoglycate ( 15 children), beclomethasone dipropionate (8 children), and prednisone (1 child) were continued unchanged.

During each 6-hour session the following were recorded: (1) Peak expiratory flow rates (PEFR) using a Wright peak flow meter. Measurements were taken immediately before treatment and at $15,30,45$, $60,90,120,180,240,300$, and 360 minutes after administration. Three measures were taken and the highest was recorded. Base values for the three treatments did not differ significantly $(P>0.05)$. (2) Pulse rates before each measurement of PEFR. (3) Throughout, observations were made of the child's behaviour and performance during exercise and normal schoolwork.

Measurements were made blind to the treatment group.

\section{Results}

Fig. 1 shows mean percentage increase in basal 


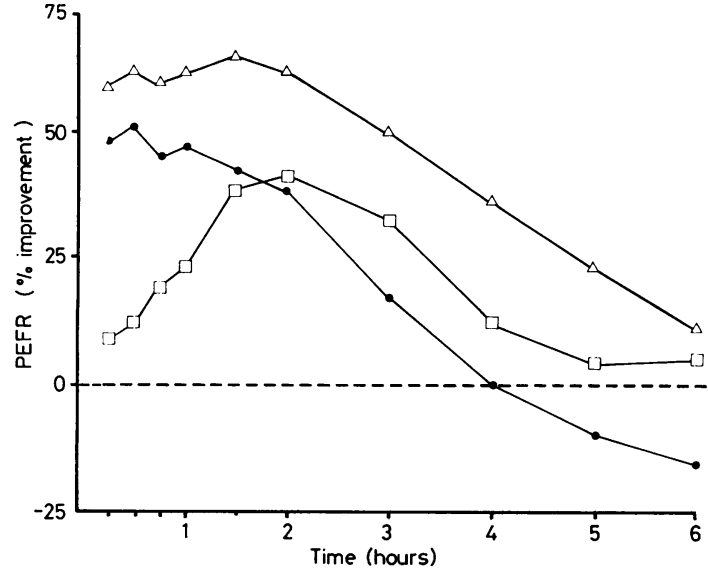

$\triangle=$ Combination salbutamol inhalational powder and tablet = Salbutamol powder alone

= Salbutamol tablet alone

Fig. 1 Mean percentage improvement in peak expiratory flow rate $(P E F R)$ with time in 18 severely asthmatic children given three different administrations of salbutamol.

PEFR for the three treatments. Inspection of the time-response distributions show that the three treatments varied in their characteristics. The inhaled treatment had a rapid onset of effect, reaching a peak value within 30 minutes of administration, but had a rapid decay with mean PEFRs returning to basal levels 4 hours after administration. Tablet treatment had a slower onset of effect, reaching a peak at about 2 hours after administration, but declining to baseline values 5 hours after treatment. The combined treatment had a rapid onset reaching a peak after 30 minutes from administration and a sustained period of action taking 6 hours to return to basal levels.

Two way analysis of variance of the repeated measures design showed: (1) A highly significant effect for time $(\mathrm{F} 9,153=22.3 ; \mathrm{P}<0.0001)$ reflecting the tendency for PEFRs to vary with time for all treatments. (2) A significant (F2, $34=12 \cdot 0 ; \mathrm{P}<$ 0.0001 ) effect for treatment indicating that the mean percentage increase in PEFR differed between treatments (mean percentage increase PEFR tablet $=19.5 \%$; mean percentage increase PEFR inhalational powder $=26.2 \%$; mean percentage increase PEFR combined $=49 \%$ ). (3) A highly significant time by treatment interaction $(\mathrm{F} 18,306=7 \cdot 38$; $P<0.0001$ ), reflecting that the time-response curves for the three treatments varied.

Fig. 1 suggests that the time-response curve for the combined therapy curve was an additive combination of the time-response curves of its tablet and inhaled

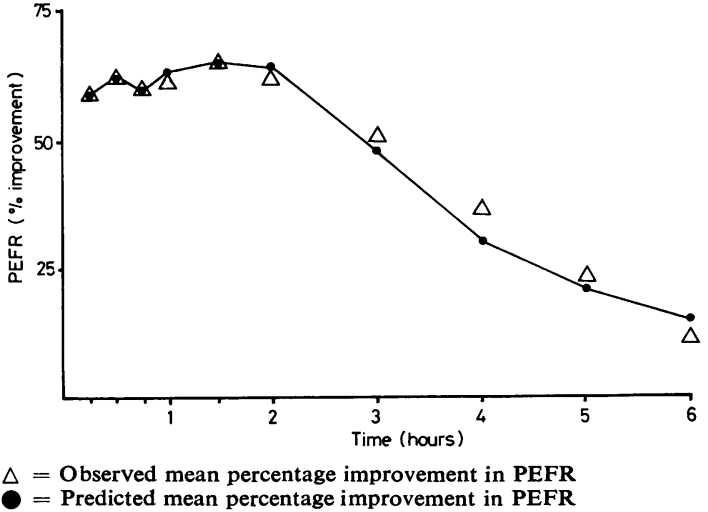

Fig. 2 Observed and predicted mean percentage improvement in peak expiratory flow rate (PEFR) with time in 18 severely asthmatic children given a combination of salbutamol inhalational powder and tablet.

powder components. To examine this further, a multiple regression equation was fitted to the data:

$$
\mathrm{C}_{\mathrm{t}}=28 \cdot 8+0.62\left(\mathrm{I}_{\mathrm{t}}\right)+0 \cdot 35\left(\mathrm{~T}_{\mathrm{t}}\right)
$$

Where $C_{t}$ was the estimated mean percentage increase in basal PEFR at time $t$ for the group receiving combined therapy; it was the observed mean percentage increase in basal PEFR for the inhalational powder alone group at time $t$ and $T_{t}$ the corresponding mean value for the tablet alone group.

Fig. 2 shows the correspondence between the observed time-response curve for the combined treatment and the time-response curve estimated from the regression equation. It is clear that there is an extremely good fit between the observed and expected values $(r=0.98)$.

The three preparations were well tolerated but children on combined or tablet treatments showed a slight increase in pulse rate (114.5 versus 109$)$ when compared with those on inhalational powder $(F 2,34=6.59 ; P<0.01)$. A child with a history of excitability and tachycardia after oral salbutamol responded in this way when given the tablet and combination treatments. Transient tremor was observed in one child on oral treatment and another became excitable for $\mathbf{3 0}$ minutes after combination therapy.

\section{Discussion}

A combined treatment in which salbutamol was administered both by inhalational powder and by tablet had superior characteristics to either tablet or inhaled treatment alone. The combined treatment showed a rapid onset of effect, reflecting the inhaled 
component, and a sustained period of action reflecting the slower acting aspects of the tablet component. Furthermore, it was possible to predict the characteristics of the combined treatment from the curves describing characteristics of each individual component, suggesting that when administered in combination, tablet and inhaled preparations act in an additive fashion. This could be ascribed to inhaled and oral treatments acting on different receptors, ${ }^{4}$ or different bio-availabilities of the two drugs at a common receptor site.

There were no significant behavioural side effects. However, as noted previously, ${ }^{56}$ the tablet and combined treatments produced a slight increase in pulse rate when compared with inhalational powder alone. As all the children had been taking salbutamol regularly for months or years, this may explain the paucity of adverse side effects. ${ }^{8}$

We thank Mrs Jo-anne Allan, research nurse, for helping with this study.

This study was supported by the National Children's Health Research Foundation. Allen \& Hanburys, Division of Glaxo Laboratories (NZ) Limited, provided the active and placebo treatments.

\section{References}

1 Walker S R, Evans M E, Richards A J, Paterson J W.
The clinical pharmacology of oral and inhaled salbutamol. Clin Pharmacol Ther 1972; 13: 861-7.

2 Francis P W J, Krastins I R B, Levison H. Oral and inhaled salbutamol in the prevention of exercise-induced bronchospasm. Pediatrics 1980; 66: 103-8.

${ }^{3}$ Grimwood K, Johnson-Barrett J J, Taylor B. Salbutamol: tablets, inhalational powder, or nebuliser? $\mathrm{Br}$ Med $\mathrm{J}$ $1981 ; 282$ : 105-6.

4 Larsson S, Svedmyr N. Broncholidating effect and side effects of beta $a_{2}$ adrenoceptor stimulants by different modes of administration (tablets, metered aerosol, and combinations thereof). Am Rev Respir Dis 1977; 116: 861-9.

5 Shim C, Williams M H, Jr. Bronchial response to oral versus aerosol metaproterenol in asthma. Ann Intern Med 1980; 93: 428-31.

6 Lee H S. Comparison of oral and aerosol adrenergic bronchodilators in asthma. J Pediatr 1981 ; 99: 805-7.

7 Williams H E, Phelan P D. Asthma. Respiratory illness in children. Blackwell: Oxford, 1975: 116-81.

8 Larsson S, Svedmyr N, Thiringer G. Lack of bronchial receptor resistance in asthmatics during long term treatment with terbutaline. J Allergy Clin Immunol 1977; 59: 93-100.

Correspondence to Dr K P Dawson, Christchurch Clinical School of Medicine, Department of Paediatrics, Christchurch Hospital, Christchurch, New Zealand.

Received 5 November 1982 